\title{
Common Fixed Points for Asymptotic Pointwise Nonexpansive Mappings in Metric and Banach Spaces
}

\author{
P. Pasom ${ }^{1}$ and B. Panyanak ${ }^{1,2}$ \\ ${ }^{1}$ Department of Mathematics, Faculty of Science, Chiang Mai University, Chiang Mai 50200, Thailand \\ ${ }^{2}$ Centre of Excellence in Mathematics, CHE, Si Ayutthaya Road, Bangkok 10400, Thailand
}

Correspondence should be addressed to B. Panyanak, banchap@chiangmai.ac.th

Received 26 October 2011; Accepted 8 December 2011

Academic Editor: Rudong Chen

Copyright (C) 2012 P. Pasom and B. Panyanak. This is an open access article distributed under the Creative Commons Attribution License, which permits unrestricted use, distribution, and reproduction in any medium, provided the original work is properly cited.

Let $C$ be a nonempty bounded closed convex subset of a complete CAT(0) space $X$. We prove that the common fixed point set of any commuting family of asymptotic pointwise nonexpansive mappings on $C$ is nonempty closed and convex. We also show that, under some suitable conditions, the sequence $\left\{x_{k}\right\}_{k=1}^{\infty}$ defined by $x_{k+1}=\left(1-t_{m k}\right) x_{k} \oplus t_{m k} T_{m}^{n_{k}} y_{(m-1) k}, y_{(m-1) k}=(1-$ $\left.t_{(m-1) k}\right) x_{k} \oplus t_{(m-1) k} T_{m-1}^{n_{k}} y_{(m-2) k}, y_{(m-2) k}=\left(1-t_{(m-2) k}\right) x_{k} \oplus t_{(m-2) k} T_{m-2}^{n_{k}} y_{(m-3) k}, \ldots, y_{2 k}=\left(1-t_{2 k}\right) x_{k} \oplus$ $t_{2 k} T_{2}^{n_{k}} y_{1 k}, y_{1 k}=\left(1-t_{1 k}\right) x_{k} \oplus t_{1 k} T_{1}^{n_{k}} y_{0 k}, y_{0 k}=x_{k}, k \in \mathbb{N}$, converges to a common fixed point of $T_{1}, T_{2}, \ldots, T_{m}$ where they are asymptotic pointwise nonexpansive mappings on $C,\left\{t_{i k}\right\}_{k=1}^{\infty}$ are sequences in $[0,1]$ for all $i=1,2, \ldots, m$, and $\left\{n_{k}\right\}$ is an increasing sequence of natural numbers. The related results for uniformly convex Banach spaces are also included.

\section{Introduction}

A mapping $T$ on a subset $C$ of a Banach space $X$ is said to be asymptotic pointwise nonexpansive if there exists a sequence of mappings $\alpha_{n}: C \rightarrow[0, \infty)$ such that

$$
\left\|T^{n} x-T^{n} y\right\| \leq \alpha_{n}(x)\|x-y\|,
$$

where $\lim _{\sup _{n \rightarrow \infty}} \alpha_{n}(x) \leq 1$, for all $x, y \in C$. This class of mappings was introduced by Kirk and $\mathrm{Xu}[1]$, where it was shown that if $C$ is a bounded closed convex subset of a uniformly convex Banach space $X$, then every asymptotic pointwise nonexpansive mapping $T: C \rightarrow C$ always has a fixed point. In 2009, Hussain and Khamsi [2] extended Kirk-Xu's result to the case of metric spaces, specifically to the so-called CAT(0) spaces. Recently, Kozlowski [3] 
defined an iterative sequence for an asymptotic pointwise nonexpansive mapping $T: C \rightarrow C$ by $x_{1} \in C$ and

$$
\begin{gathered}
x_{k+1}=\left(1-t_{k}\right) x_{k}+t_{k} T^{n_{k}} y_{k}, \\
y_{k}=\left(1-s_{k}\right) x_{k}+s_{k} T^{n_{k}} x_{k}, \quad k \in \mathbb{N},
\end{gathered}
$$

where $\left\{t_{k}\right\}$ and $\left\{s_{k}\right\}$ are sequences in $[0,1]$ and $\left\{n_{k}\right\}$ is an increasing sequence of natural numbers. He proved, under some suitable assumptions, that the sequence $\left\{x_{k}\right\}$ defined by (1.2) converges weakly to a fixed point of $T$ where $X$ is a uniformly convex Banach space which satisfies the Opial condition and $\left\{x_{k}\right\}$ converges strongly to a fixed point of $T$ provided $T^{r}$ is a compact mapping for some $r \in \mathbb{N}$. On the other hand, Khan et al. [4] studied the iterative process defined by

$$
\begin{gathered}
x_{n+1}=\left(1-\alpha_{m n}\right) x_{n}+\alpha_{m n} T_{m}^{n} y_{(m-1) n}, \\
y_{(m-1) n}=\left(1-\alpha_{(m-1) n}\right) x_{n}+\alpha_{(m-1) n} T_{m-1}^{n} y_{(m-2) n}, \\
y_{(m-2) n}=\left(1-\alpha_{(m-2) n}\right) x_{n}+\alpha_{(m-2) n} T_{m-2}^{n} y_{(m-3) n} \\
\vdots \\
y_{2 n}=\left(1-\alpha_{2 n}\right) x_{n}+\alpha_{2 n} T_{2}^{n} y_{1 n}, \\
y_{1 n}=\left(1-\alpha_{1 n}\right) x_{n}+\alpha_{1 n} T_{1}^{n} y_{0 n}, \\
y_{0 n}=x_{n}, \quad n \in \mathbb{N},
\end{gathered}
$$

where $T_{1}, \ldots, T_{m}$ are asymptotically quasi-nonexpansive mappings on $C$ and $\left\{\alpha_{i n}\right\}_{n=1}^{\infty}$ are sequences in $[0,1]$ for all $i=1,2, \ldots, m$.

In this paper, motivated by the results mentioned above, we ensure the existence of common fixed points for a family of asymptotic pointwise nonexpansive mappings in a CAT(0) space. Furthermore, we obtain $\Delta$ and strong convergence theorems of a sequence defined by

$$
\begin{gathered}
x_{k+1}=\left(1-t_{m k}\right) x_{k} \oplus t_{m k} T_{m}^{n_{k}} y_{(m-1) k}, \\
y_{(m-1) k}=\left(1-t_{(m-1) k}\right) x_{k} \oplus t_{(m-1) k} T_{m-1}^{n_{k}} y_{(m-2) k}, \\
y_{(m-2) k}=\left(1-t_{(m-2) k}\right) x_{k} \oplus t_{(m-2) k} T_{m-2}^{n_{k}} y_{(m-3) k}, \\
\vdots \\
y_{2 k}=\left(1-t_{2 k}\right) x_{k} \oplus t_{2 k} T_{2}^{n_{k}} y_{1 k}, \\
y_{1 k}=\left(1-t_{1 k}\right) x_{k} \oplus t_{1 k} T_{1}^{n_{k}} y_{0 k}, \\
y_{0 k}=x_{k}, \quad k \in \mathbb{N},
\end{gathered}
$$

where $T_{1}, \ldots, T_{m}$ are asymptotic pointwise nonexpansive mappings on a subset $C$ of a complete CAT(0) space and $\left\{t_{i k}\right\}_{k=1}^{\infty}$ are sequences in $[0,1]$ for all $i=1,2, \ldots, m$, and $\left\{n_{k}\right\}$ is an increasing sequence of natural numbers. We also note that our method can be used to prove the analogous results for uniformly convex Banach spaces. 


\section{Preliminaries}

A metric space $X$ is a CAT(0) space if it is geodesically connected and if every geodesic triangle in $X$ is at least as "thin" as its comparison triangle in the Euclidean plane. It is well-known that any complete, simply connected Riemannian manifold having nonpositive sectional curvature is a CAT( 0 ) space. Other examples include Pre-Hilbert spaces (see [5]), $\mathbb{R}$ trees (see [6]), Euclidean buildings (see [7]), and the complex Hilbert ball with a hyperbolic metric (see [8]). For a thorough discussion of these spaces and of the fundamental role they play in geometry, we refer the reader to Bridson and Haefliger [5].

Fixed point theory in CAT(0) spaces was first studied by Kirk (see $[9,10])$. He showed that every nonexpansive (single-valued) mapping defined on a bounded closed convex subset of a complete CAT(0) space always has a fixed point. Since then the fixed point theory for single-valued and multivalued mappings in CAT(0) spaces has been rapidly developed, and many papers have appeared (see, e.g., [2,11-22] and the references therein). It is worth mentioning that fixed point theorems in CAT(0) spaces (specially in $\mathbb{R}$-trees) can be applied to graph theory, biology, and computer science (see, e.g., [6, 23-26]).

Let $(X, d)$ be a metric space. A geodesic path joining $x \in X$ to $y \in X$ (or, more briefly, a geodesic from $x$ to $y)$ is a map $c$ from a closed interval $[0, l] \subset \mathbb{R}$ to $X$ such that $c(0)=x, c(l)=$ $y$, and $d\left(c(t), c\left(t^{\prime}\right)\right)=\left|t-t^{\prime}\right|$ for all $t, t^{\prime} \in[0, l]$. In particular, $c$ is an isometry and $d(x, y)=l$. The image $\alpha$ of $c$ is called a geodesic (or metric) segment joining $x$ and $y$. When it is unique, this geodesic is denoted by $[x, y]$. The space $(X, d)$ is said to be a geodesic space if every two points of $X$ are joined by a geodesic, and $X$ is said to be uniquely geodesic if there is exactly one geodesic joining $x$ and $y$ for each $x, y \in X$. A subset $Y \subset X$ is said to be convex if $Y$ includes every geodesic segment joining any two of its points.

A geodesic triangle $\Delta\left(x_{1}, x_{2}, x_{3}\right)$ in a geodesic space $(X, d)$ consists of three points $x_{1}$, $x_{2}, x_{3}$ in $X$ (the vertices of $\Delta$ ) and a geodesic segment between each pair of vertices (the edges of $\Delta)$. A comparison triangle for geodesic triangle $\Delta\left(x_{1}, x_{2}, x_{3}\right)$ in $(X, d)$ is a triangle $\bar{\Delta}\left(x_{1}, x_{2}, x_{3}\right):=\Delta\left(\bar{x}_{1}, \bar{x}_{2}, \bar{x}_{3}\right)$ in the Euclidean plane $\mathbb{E}^{2}$ such that $d_{\mathbb{E}^{2}}\left(\bar{x}_{i}, \bar{x}_{j}\right)=d\left(x_{i}, x_{j}\right)$ for $i, j \in\{1,2,3\}$.

A geodesic space is said to be a CAT(0) space if all geodesic triangles satisfy the following comparison axiom.

CAT(0): Let $\Delta$ be a geodesic triangle in $X$, and let $\bar{\Delta}$ be a comparison triangle for $\Delta$. Then, $\Delta$ is said to satisfy the CAT(0) inequality if for all $x, y \in \Delta$ and all comparison points $\bar{x}, \bar{y} \in \bar{\triangle}$,

$$
d(x, y) \leq d_{\mathbb{E}^{2}}(\bar{x}, \bar{y})
$$

Let $x, y \in X$, by Lemma 2.1(iv) of [14] for each $t \in[0,1]$, there exists a unique point $z \in[x, y]$ such that

$$
d(x, z)=t d(x, y), \quad d(y, z)=(1-t) d(x, y) .
$$

We will use the notation $(1-t) x \oplus t y$ for the unique point $z$ satisfying (2.2). We now collect some elementary facts about CAT( 0$)$ spaces. 
Lemma 2.1. Let $X$ be a complete $C A T(0)$ space.

(i) [5, Proposition 2.4] If $C$ is a nonempty closed convex subset of $X$, then, for every $x \in X$, there exists a unique point $P(x) \in C$ such that $d(x, P(x))=\inf \{d(x, y): y \in C\}$. Moreover, the map $x \mapsto P(x)$ is a nonexpansive retract from $X$ onto $C$.

(ii) [14, Lemma 2.4] For $x, y, z \in X$ and $t \in[0,1]$, we have

$$
d((1-t) x \oplus t y, z) \leq(1-t) d(x, z)+t d(y, z)
$$

(iii) [14, Lemma 2.5] For $x, y, z \in X$ and $t \in[0,1]$, we have

$$
d((1-t) x \oplus t y, z)^{2} \leq(1-t) d(x, z)^{2}+t d(y, z)^{2}-t(1-t) d(x, y)^{2} .
$$

We now give the concept of $\Delta$-convergence and collect some of its basic properties. Let $\left\{x_{n}\right\}$ be a bounded sequence in a $\operatorname{CAT}(0)$ space $X$. For $x \in X$, we set

$$
r\left(x,\left\{x_{n}\right\}\right)=\limsup _{n \rightarrow \infty} d\left(x, x_{n}\right)
$$

The asymptotic radius $r\left(\left\{x_{n}\right\}\right)$ of $\left\{x_{n}\right\}$ is given by

$$
r\left(\left\{x_{n}\right\}\right)=\inf \left\{r\left(x,\left\{x_{n}\right\}\right): x \in X\right\},
$$

and the asymptotic center $A\left(\left\{x_{n}\right\}\right)$ of $\left\{x_{n}\right\}$ is the set

$$
A\left(\left\{x_{n}\right\}\right)=\left\{x \in X: r\left(x,\left\{x_{n}\right\}\right)=r\left(\left\{x_{n}\right\}\right)\right\} .
$$

It is known from Proposition 7 of [27] that, in a CAT(0) space, $A\left(\left\{x_{n}\right\}\right)$ consists of exactly one point.

Definition 2.2 (see $[28,29]$ ). A sequence $\left\{x_{n}\right\}$ in a $\mathrm{CAT}(0)$ space $X$ is said to $\Delta$-converge to $x \in X$ if $x$ is the unique asymptotic center of $\left\{u_{n}\right\}$ for every subsequence $\left\{u_{n}\right\}$ of $\left\{x_{n}\right\}$. In this case, we write $\Delta-\lim _{n} x_{n}=x$ and call $x$ the $\Delta$-limit of $\left\{x_{n}\right\}$.

Lemma 2.3. Let $X$ be a complete $C A T(0)$ space.

(i) [28, page 3690] Every bounded sequence in X has a $\Delta$-convergent subsequence.

(ii) [30, Proposition 2.1] If $C$ is a closed convex subset of a complete CAT(0) space and if $\left\{x_{n}\right\}$ is a bounded sequence in $C$, then the asymptotic center of $\left\{x_{n}\right\}$ is in $C$.

(iii) [14, Lemma 2.8] If $\left\{x_{n}\right\}$ is a bounded sequence in a complete $C A T(0)$ space with $A\left(\left\{x_{n}\right\}\right)=$ $\{x\}$ and $\left\{u_{n}\right\}$ is a subsequence of $\left\{x_{n}\right\}$ with $A\left(\left\{u_{n}\right\}\right)=\{u\}$ and the sequence $\left\{d\left(x_{n}, u\right)\right\}$ converges, then $x=u$.

Recall that a mapping $T: X \rightarrow X$ is said to be nonexpansive [31] if

$$
d(T x, T y) \leq d(x, y), \quad \forall x, y \in X,
$$


where $T$ is called asymptotically nonexpansive [32] if there is a sequence $\left\{k_{n}\right\}$ of positive numbers with the property $\lim _{n \rightarrow \infty} k_{n}=1$ and such that

$$
d\left(T^{n} x, T^{n} y\right) \leq k_{n} d(x, y), \quad \forall n \geq 1, x, y \in X,
$$

where $T$ is called an asymptotic pointwise nonexpansive mapping [1] if there exists a sequence of functions $\alpha_{n}: X \rightarrow[0, \infty)$ such that

$$
d\left(T^{n} x, T^{n} y\right) \leq \alpha_{n}(x) d(x, y), \quad \forall n \geq 1, x, y \in X
$$

where $\lim \sup _{n \rightarrow \infty} \alpha_{n}(x) \leq 1$. The following implications hold.

$$
\begin{aligned}
T \text { is nonexpansive } & \Longrightarrow T \text { is asymptotically nonexpansive } \\
& \Longrightarrow T \text { is asymptotic pointwise nonexpansive. }
\end{aligned}
$$

A point $x \in X$ is called a fixed point of $T$ if $x=T x$. We shall denote by $F(T)$ the set of fixed points of $T$. The existence of fixed points for asymptotic pointwise nonexpansive mappings in CAT(0) spaces was proved by Hussain and Khamsi [2] as the following result.

Theorem 2.4. Let $C$ be a nonempty bounded closed convex subset of a complete CAT(0) space X. Suppose that $T: C \rightarrow C$ is an asymptotic pointwise nonexpansive mapping. Then, $F(T)$ is nonempty closed and convex.

\section{Existence Theorems}

Let $M$ be a metric space and $\mathcal{F}$ a family of subsets of $M$. Then, we say that $\mathcal{F}$ defines a convexity structure on $M$ if it contains the closed balls and is stable by intersection.

Definition 3.1 (see [2]). Let $\mathcal{F}$ be a convexity structure on $M$. We will say that $\mathcal{F}$ is compact if any family $\left\{A_{\alpha}\right\}_{\alpha \in \Gamma}$ of elements of $\mathcal{F}$ has a nonempty intersection provided $\bigcap_{\alpha \in F} A_{\alpha} \neq \emptyset$ for any finite subset $F \subset \Gamma$.

Let $X$ be a complete $C A T(0)$ space. We denote by $\mathcal{C}(X)$ the family of all closed convex subsets of $X$. Then, $\mathcal{C}(X)$ is a compact convexity structure on $X$ (see, e.g., [2]).

The following theorem is an extension of Theorem 4.3 in [33]. For an analog of this result in uniformly convex Banach spaces, see [34].

Theorem 3.2. Let $C$ be a nonempty bounded closed and convex subset of a complete $C A T(0)$ space $X$. Then, for any commuting family $\mathcal{S}$ of asymptotic pointwise nonexpansive mappings on $C$, the set $\mathcal{F}(\mathcal{S})$ of common fixed points of $\mathcal{S}$ is nonempty closed and convex.

Proof. Let $\tau$ be the family of all finite intersections of the fixed point sets of mappings in the commutative family $\mathcal{S}$. We first show that $\tau$ has the finite intersection property. Let $T_{1}, T_{2}, \ldots, T_{n} \in \mathcal{S}$. By Theorem 2.4, $F\left(T_{1}\right)$ is a nonempty closed and convex subset of $C$. We 
assume that $A:=\bigcap_{j=1}^{k-1} F\left(T_{j}\right)$ is nonempty closed and convex for some $k \in \mathbb{N}$ with $1<k \leq n$. For $x \in A$ and $j \in \mathbb{N}$ with $1 \leq j<k$, we have

$$
T_{k}(x)=T_{k} \circ T_{j}(x)=T_{j} \circ T_{k}(x) .
$$

Thus, $T_{k}(x)$ is a fixed point of $T_{j}$, which implies that $T_{k}(x) \in A$; therefore, $A$ is invariant under $T_{k}$. Again, by Theorem $2.4, T_{k}$ has a fixed point in $A$, that is,

$$
\bigcap_{j=1}^{k} F\left(T_{j}\right)=F\left(T_{k}\right) \bigcap A \neq \emptyset .
$$

By induction, $\bigcap_{j=1}^{n} F\left(T_{j}\right) \neq \emptyset$. Hence, $\tau$ has the finite intersection property. Since $\mathcal{C}(X)$ is compact,

$$
\mathcal{F}(\mathcal{S})=\bigcap_{T \in \mathcal{\tau}} T \neq \emptyset
$$

Obviously, the set is closed and convex.

As a consequence of Lemma 2.1(i) and Theorem 3.2, we obtain an analog of Bruck's theorem [35].

Corollary 3.3. Let $C$ be a nonempty bounded closed and convex subset of a complete $C A T(0)$ space $X$. Then, for any commuting family $\mathcal{S}$ of nonexpansive mappings on $C$, the set $\mathcal{F}(\mathcal{S})$ of common fixed points of $\mathcal{S}$ is a nonempty nonexpansive retract of $C$.

\section{Convergence Theorems}

Throughout this section, $X$ stands for a complete CAT(0) space. Let $C$ be a closed convex subset of $X$. We shall denote by $\tau(C)$ the class of all asymptotic pointwise nonexpansive mappings from $C$ into $C$. Let $T_{1}, \ldots, T_{m} \in \tau(C)$, without loss of generality, we can assume that there exists a sequence of mappings $\alpha_{n}: C \rightarrow[0, \infty)$ such that for all $x, y \in C, i=1, \ldots, m$, and $n \in \mathbb{N}$, we have

$$
d\left(T_{i}^{n} x, T_{i}^{n} y\right) \leq \alpha_{n}(x) d(x, y), \quad \limsup _{n \rightarrow \infty} \alpha_{n}(x) \leq 1
$$

Let $a_{n}(x)=\max \left\{\alpha_{n}(x), 1\right\}$. Again, without loss of generality, we can assume that

$$
d\left(T_{i}^{n} x, T_{i}^{n} y\right) \leq a_{n}(x) d(x, y), \quad \lim _{n \rightarrow \infty} a_{n}(x)=1, \quad a_{n}(x) \geq 1,
$$

for all $x, y \in C, i=1, \ldots, m$, and $n \in \mathbb{N}$. We define $b_{n}(x)=a_{n}(x)-1$, then, for each $x \in C$, we have $\lim _{n \rightarrow \infty} b_{n}(x)=0$. 
The following definition is a mild modification of [3, Definition 2.3].

Definition 4.1. Define $\tau_{r}(C)$ as a class of all $T \in \tau(C)$ such that

$$
\sum_{n=1}^{\infty} \sup _{x \in C} b_{n}(x)<\infty
$$

$a_{n}$ is a bounded function for every $n \in \mathbb{N}$.

Let $T_{1}, \ldots, T_{m} \in \tau_{r}(C)$, and let $\left\{t_{i k}\right\}_{k=1}^{\infty} \subset(0,1)$ be bounded away from 0 and 1 for all $i=1,2, \ldots, m$, and $\left\{n_{k}\right\}$ an increasing sequence of natural numbers. Let $x_{1} \in C$, and define a sequence $\left\{x_{k}\right\}$ in $C$ as

$$
\begin{gathered}
x_{k+1}=\left(1-t_{m k}\right) x_{k} \oplus t_{m k} T_{m}^{n_{k}} y_{(m-1) k}, \\
y_{(m-1) k}=\left(1-t_{(m-1) k}\right) x_{k} \oplus t_{(m-1) k} T_{m-1}^{n_{k}} y_{(m-2) k}, \\
y_{(m-2) k}=\left(1-t_{(m-2) k}\right) x_{k} \oplus t_{(m-2) k} T_{m-2}^{n_{k}} y_{(m-3) k}, \\
\vdots \\
y_{2 k}=\left(1-t_{2 k}\right) x_{k} \oplus t_{2 k} T_{2}^{n_{k}} y_{1 k}, \\
y_{1 k}=\left(1-t_{1 k}\right) x_{k} \oplus t_{1 k} T_{1}^{n_{k}} y_{0 k}, \\
y_{0 k}=x_{k}, \quad k \in \mathbb{N} .
\end{gathered}
$$

We say that the sequence $\left\{x_{k}\right\}$ in (4.4) is well defined if $\lim _{\sup _{k \rightarrow \infty}} a_{n_{k}}\left(x_{k}\right)=1$. As in [3], we observe that $\lim _{k \rightarrow \infty} a_{k}(x)=1$ for every $x \in C$. Hence, we can always choose a subsequence $\left\{a_{n_{k}}\right\}$ which makes $\left\{x_{k}\right\}$ well defined.

Lemma 4.2 (see [36, Lemma 2.2]). Let $\left\{a_{n}\right\}$ and $\left\{u_{n}\right\}$ be sequences of nonnegative real numbers satisfying

$$
a_{n+1} \leq\left(1+u_{n}\right) a_{n}, \quad \forall n \in \mathbb{N}, \sum_{n=1}^{\infty} u_{n}<\infty
$$

Then, (i) $\lim _{n} a_{n}$ exists, (ii) if $\liminf _{n} a_{n}=0$, then $\lim _{n} a_{n}=0$.

Lemma 4.3 (see $[37,38]$ ). Suppose $\left\{t_{n}\right\}$ is a sequence in $[b, c]$ for some $b, c \in(0,1)$ and $\left\{u_{n}\right\},\left\{v_{n}\right\}$ are sequences in $X$ such that $\lim \sup _{n} d\left(u_{n}, w\right) \leq r, \limsup _{n} d\left(v_{n}, w\right) \leq r$, and $\lim _{n} d\left(\left(1-t_{n}\right) u_{n} \oplus\right.$ $\left.t_{n} v_{n}, w\right)=r$ for some $r \geq 0$. Then,

$$
\lim _{n \rightarrow \infty} d\left(u_{n}, v_{n}\right)=0
$$

Lemma 4.4. Let $C$ be a nonempty closed convex subset of $X$ and $T_{1}, \ldots, T_{m} \in \tau_{r}(C)$. Let $\left\{t_{i k}\right\}_{k=1}^{\infty} \subset[a, b] \subset(0,1)$ and $\left\{n_{k}\right\} \subset \mathbb{N}$ be such that $\left\{x_{k}\right\}$ in (4.4) is well defined. Assume that $F:=\bigcap_{i=1}^{m} F\left(T_{i}\right) \neq \emptyset$. Then,

(a) there exists a sequence $\left\{v_{k}\right\}$ in $[0, \infty)$ such that $\sum_{k=1}^{\infty} v_{k}<\infty$ and $d\left(x_{k+1}, p\right) \leq$ $\left(1+v_{k}\right)^{m} d\left(x_{k}, p\right)$, for all $p \in F$ and all $k \in \mathbb{N}$, 
(b) there exists a constant $M>0$ such that $d\left(x_{k+l}, p\right) \leq M d\left(x_{k}, p\right)$, for all $p \in F$ and $k, l \in \mathbb{N}$.

Proof. (a) Let $p \in F$ and $v_{k}=\sup _{x \in C} b_{n_{k}}(x)$ for all $k \in \mathbb{N}$. Since $\sum_{k=1}^{\infty} \sup _{x \in C} b_{n_{k}}(x)<\infty$, we have $\sum_{k=1}^{\infty} v_{k}<\infty$. Now,

$$
\begin{aligned}
d\left(y_{1 k}, p\right) & \leq\left(1-t_{1 k}\right) d\left(x_{k}, p\right)+t_{1 k} d\left(T_{1}^{n_{k}} x_{k}, p\right) \\
& \leq\left(1-t_{1 k}\right) d\left(x_{k}, p\right)+t_{1 k}\left(1+b_{n_{k}}(p)\right) d\left(x_{k}, p\right) \\
& =\left(1+t_{1 k} b_{n_{k}}(p)\right) d\left(x_{k}, p\right) \\
& \leq\left(1+v_{k}\right) d\left(x_{k}, p\right) .
\end{aligned}
$$

Suppose that $d\left(y_{j k}, p\right) \leq\left(1+v_{k}\right)^{j} d\left(x_{k}, p\right)$ holds for some $1 \leq j \leq m-2$. Then,

$$
\begin{aligned}
d\left(y_{(j+1) k}, p\right) & \leq\left(1-t_{(j+1) k}\right) d\left(x_{k}, p\right)+t_{(j+1) k} d\left(T_{j+1}^{n_{k}} y_{j k}, p\right) \\
& \leq\left(1-t_{(j+1) k}\right) d\left(x_{k}, p\right)+t_{(j+1) k}\left(1+b_{n_{k}}(p)\right) d\left(y_{j k}, p\right) \\
& \leq\left(1-t_{(j+1) k}\right) d\left(x_{k}, p\right)+t_{(j+1) k}\left(1+v_{k}\right)^{j+1} d\left(x_{k}, p\right) \\
& =\left[1-t_{(j+1) k}+t_{(j+1) k}\left(1+\sum_{r=1}^{j+1} \frac{(j+1) j \cdots(j+2-r)}{r !} v_{k}^{r}\right)\right] d\left(x_{k}, p\right) \\
& =\left[1+t_{(j+1) k} \sum_{r=1}^{j+1} \frac{(j+1) j \cdots(j+2-r)}{r !} v_{k}^{r}\right] d\left(x_{k}, p\right) \\
& \leq\left(1+v_{k}\right)^{j+1} d\left(x_{k}, p\right) .
\end{aligned}
$$

By induction, we have

$$
d\left(y_{i k}, p\right) \leq\left(1+v_{k}\right)^{i} d\left(x_{k}, p\right), \quad \forall i=1,2, \ldots, m-1
$$

This implies

$$
\begin{aligned}
d\left(x_{k+1}, p\right) & \leq\left(1-t_{m k}\right) d\left(x_{k}, p\right)+t_{m k} d\left(T_{m}^{n_{k}} y_{(m-1) k}, p\right) \\
& \leq\left(1-t_{m k}\right) d\left(x_{k}, p\right)+t_{m k}\left(1+b_{n_{k}}(p)\right) d\left(y_{(m-1) k}, p\right) \\
& \leq\left(1-t_{m k}\right) d\left(x_{k}, p\right)+t_{m k}\left(1+v_{k}\right)\left(1+v_{k}\right)^{m-1} d\left(x_{k}, p\right) \\
& \leq\left(1-t_{m k}\right) d\left(x_{k}, p\right)+t_{m k}\left(1+v_{k}\right)^{m} d\left(x_{k}, p\right) \\
& =\left[1-t_{m k}+t_{m k}\left(1+\sum_{r=1}^{m} \frac{m(m-1) \cdots(m-r+1)}{r !} v_{k}^{r}\right)\right] d\left(x_{k}, p\right) \\
& =\left[1+t_{m k} \sum_{r=1}^{m} \frac{m(m-1) \cdots(m-r+1)}{r !} v_{k}^{r}\right] d\left(x_{k}, p\right) \\
& \leq\left(1+v_{k}\right)^{m} d\left(x_{k}, p\right) .
\end{aligned}
$$

This completes the proof of (a). 
(b) We observe that $(1+\alpha)^{n} \leq e^{n \alpha}$ holds for all $n \in \mathbb{N}$ and $\alpha \geq 0$. Thus, by (a), for $k, l \in \mathbb{N}$, we have

$$
\begin{aligned}
d\left(x_{k+l}, p\right) & \leq\left(1+v_{k+l-1}\right)^{m} d\left(x_{k+l-1}, p\right) \\
& \leq \exp \left\{m v_{k+l-1}\right\} d\left(x_{k+l-1}, p\right) \leq \cdots \leq \exp \left\{m \sum_{i=1}^{k+l-1} v_{i}\right\} d\left(x_{k}, p\right) \\
& \leq \exp \left\{m \sum_{i=1}^{\infty} v_{i}\right\} d\left(x_{k}, p\right) .
\end{aligned}
$$

The proof is complete by setting $M=\exp \left\{m \sum_{i=1}^{\infty} v_{i}\right\}$.

Theorem 4.5. Let $C$ be a nonempty closed convex subset of $X$ and $T_{1}, \ldots, T_{m} \in \tau_{r}(C)$. Let $\left\{t_{i k}\right\}_{k=1}^{\infty} \subset$ $[a, b] \subset(0,1)$ and $\left\{n_{k}\right\} \subset \mathbb{N}$ be such that $\left\{x_{k}\right\}$ in (4.4) is well defined. Assume that $F \neq \emptyset$. Then, $\left\{x_{k}\right\}$ converges to some point in $F$ if and only if $\liminf _{k \rightarrow \infty} d\left(x_{k}, F\right)=0$, where $d(x, F)=\inf _{p \in F} d(x, p)$.

Proof. The necessity is obvious. Now, we prove the sufficiency. From Lemma 4.4(a), we have

$$
d\left(x_{k+1}, p\right) \leq\left(1+v_{k}\right)^{m} d\left(x_{k}, p\right), \quad \forall p \in F, \forall k \in \mathbb{N} .
$$

This implies

$$
d\left(x_{k+1}, F\right) \leq\left(1+v_{k}\right)^{m} d\left(x_{k}, F\right)=\left(1+\sum_{r=1}^{m} \frac{m(m-1) \cdots(m-r+1)}{r !} v_{k}^{r}\right) d\left(x_{k}, F\right)
$$

Since $\sum_{k=1}^{\infty} v_{k}<\infty$, then $\sum_{k=1}^{\infty} \sum_{r=1}^{m}(m(m-1) \cdots(m-r+1) / r$ ! $) v_{k}^{r}<\infty$. By Lemma 4.2(ii), we get $\lim _{k \rightarrow \infty} d\left(x_{k}, F\right)=0$. Next, we show that $\left\{x_{k}\right\}$ is a Cauchy sequence. From Lemma 4.4(b), there exists $M>0$ such that

$$
d\left(x_{k+l}, p\right) \leq M d\left(x_{k}, p\right), \quad \forall p \in F, k, l \in \mathbb{N} .
$$

Since $\lim _{k \rightarrow \infty} d\left(x_{k}, F\right)=0$, for each $\varepsilon>0$, there exists $k_{1} \in \mathbb{N}$ such that

$$
d\left(x_{k}, F\right)<\frac{\varepsilon}{2 M}, \quad \forall k \geq k_{1} .
$$

Hence, there exists $z_{1} \in F$ such that

$$
d\left(x_{k_{1}}, z_{1}\right)<\frac{\varepsilon}{2 M}
$$


By (4.14) and (4.16), for $k \geq k_{1}$, we have

$$
\begin{aligned}
d\left(x_{k+l}, x_{k}\right) & \leq d\left(x_{k+l}, z_{1}\right)+d\left(x_{k}, z_{1}\right) \\
& \leq M d\left(x_{k_{1}}, z_{1}\right)+\operatorname{Md}\left(x_{k_{1}}, z_{1}\right) \\
& <2 M\left(\frac{\varepsilon}{2 M}\right) \\
& =\varepsilon .
\end{aligned}
$$

This shows that $\left\{x_{k}\right\}$ is a Cauchy sequence and so converges to some $q \in C$. We next show that $q \in F$. Let $L=\sup \left\{a_{1}(x): x \in C\right\}$. Then, for each $\epsilon>0$, there exists $k_{2} \in \mathbb{N}$ such that

$$
d\left(x_{k}, q\right)<\frac{\epsilon}{2(1+L)}, \quad \forall k \geq k_{2} .
$$

Since $\lim _{k \rightarrow \infty} d\left(x_{k}, F\right)=0$, there exists $k_{3} \geq k_{2}$ such that

$$
d\left(x_{k}, F\right)<\frac{\epsilon}{2(1+L)}, \quad \forall k \geq k_{3} .
$$

Thus, there exists $z_{2} \in F$ such that

$$
d\left(x_{k_{3}}, z_{2}\right)<\frac{\epsilon}{2(1+L)}
$$

By (4.18) and (4.20), for each $i=1,2, \ldots, m$, we have

$$
\begin{aligned}
d\left(T_{i} q, q\right) & \leq d\left(T_{i} q, T_{i} x_{k_{3}}\right)+d\left(T_{i} x_{k_{3}}, z_{2}\right)+d\left(z_{2}, x_{k_{3}}\right)+d\left(x_{k_{3}}, q\right) \\
& \leq L d\left(x_{k_{3}}, q\right)+L d\left(x_{k_{3}}, z_{2}\right)+d\left(x_{k_{3}}, z_{2}\right)+d\left(x_{k_{3}}, q\right) \\
& \leq(1+L) d\left(x_{k_{3}}, q\right)+(1+L) d\left(x_{k_{3}}, z_{2}\right) \\
& <(1+L) \frac{\epsilon}{2(1+L)}+(1+L) \frac{\epsilon}{2(1+L)} \\
& =\epsilon .
\end{aligned}
$$

Since $\epsilon$ is arbitrary, we have $T_{i} q=q$ for all $i=1,2, \ldots, m$. Hence, $q \in F$.

As an immediate consequence of Theorem 4.5, we obtain the following.

Corollary 4.6. Let $C$ be a nonempty closed convex subset of $X$ and $T_{1}, \ldots, T_{m} \in \tau_{r}(C)$. Let $\left\{t_{i k}\right\}_{k=1}^{\infty} \subset$ $[a, b] \subset(0,1)$ and $\left\{n_{k}\right\} \subset \mathbb{N}$ be such that $\left\{x_{k}\right\}$ in (4.4) is well defined. Assume that $F \neq \emptyset$. Then, $\left\{x_{k}\right\}$ converges to a point $p \in F$ if and only if there exists a subsequence $\left\{x_{k_{j}}\right\}$ of $\left\{x_{k}\right\}$ which converges to $p$.

Definition 4.7. A strictly increasing sequence $\left\{n_{k}\right\} \subset \mathbb{N}$ is called quasiperiodic [39] if the sequence $\left\{n_{k+1}-n_{k}\right\}$ is bounded or equivalently if there exists a number $p \in \mathbb{N}$ such that any block of $p$ consecutive natural numbers must contain a term of the sequence $\left\{n_{k}\right\}$. The smallest of such numbers $p$ will be called a quasiperiod of $\left\{n_{k}\right\}$. 
Journal of Applied Mathematics

Lemma 4.8. Let $C$ be a nonempty closed convex subset of $X$ and $T_{1}, \ldots, T_{m} \in \tau_{r}(C)$. Let $\left\{t_{i k}\right\}_{k=1}^{\infty} \subset$ $[\delta, 1-\delta]$ for some $\delta \in(0,1 / 2)$ and $\left\{n_{k}\right\} \subset \mathbb{N}$ be such that $\left\{x_{k}\right\}$ in (4.4) is well defined. Then,

(i) $\lim _{k \rightarrow \infty} d\left(x_{k}, p\right)$ exists for all $p \in F$,

(ii) $\lim _{k \rightarrow \infty} d\left(x_{k}, T_{j}^{n_{k}} y_{(j-1) k}\right)=0$, for all $j=1,2, \ldots, m$,

(iii) if the set $2=\left\{k \in \mathbb{N}: n_{k+1}=1+n_{k}\right\}$ is quasiperiodic, then $\lim _{k \rightarrow \infty} d\left(x_{k}, T_{j} x_{k}\right)=0$, for all $j=1,2, \ldots, m$.

Proof. (i) Follows from Lemmas 4.2(i) and 4.4(a).

(ii) Let $p \in F$, then, by (i), we have $\lim _{k \rightarrow \infty} d\left(x_{k}, p\right)$ exists. Let

$$
\lim _{k \rightarrow \infty} d\left(x_{k}, p\right)=c
$$

By (4.9) and (4.22), we get that

$$
\limsup _{k \rightarrow \infty} d\left(y_{j k}, p\right) \leq c, \quad \text { for } 1 \leq j \leq m-1 .
$$

Note that

$$
\begin{aligned}
d\left(x_{k+1}, p\right) \leq & \left(1-t_{m k}\right) d\left(x_{k}, p\right)+t_{m k} d\left(T_{m}^{n_{k}} y_{(m-1) k}, p\right) \\
\leq & \left(1-t_{m k}\right) d\left(x_{k}, p\right)+t_{m k}\left(1+v_{k}\right) d\left(y_{(m-1) k}, p\right) \\
& \vdots \\
& \leq\left(1-t_{m k} t_{(m-1) k} \cdots t_{(j+1) k}\right)\left(1+v_{k}\right)^{m-j} d\left(x_{k}, p\right) \\
& +t_{m k} t_{(m-1) k} \cdots t_{(j+1) k}\left(1+v_{k}\right)^{m-j} d\left(y_{j k}, p\right) .
\end{aligned}
$$

Thus,

$$
d\left(x_{k}, p\right) \leq \frac{d\left(x_{k}, p\right)}{\delta^{m-j}}-\frac{d\left(x_{k+1}, p\right)}{\delta^{m-j}\left(1+v_{k}\right)^{m-j}}+d\left(y_{j k}, p\right),
$$

so that

$$
c \leq \liminf _{k \rightarrow \infty} d\left(y_{j k}, p\right), \quad \text { for } 1 \leq j \leq m-1 .
$$

From (4.23) and (4.26), we have

$$
\lim _{k \rightarrow \infty} d\left(y_{j k}, p\right)=c, \quad \text { for each } j=1,2, \ldots, m-1 .
$$

That is

$$
\lim _{k \rightarrow \infty} d\left(\left(1-t_{j k}\right) x_{k} \oplus t_{j k} T_{j}^{n_{k}} y_{(j-1) k}, p\right)=c,
$$

for each $j=1,2, \ldots, m-1$. 
We also obtain from (4.23) that

$$
\limsup _{k \rightarrow \infty} d\left(T_{j}^{n_{k}} y_{(j-1) k}, p\right) \leq c, \quad \text { for each } j=1,2, \ldots, m-1
$$

By Lemma 4.3, we get that

$$
\lim _{k \rightarrow \infty} d\left(T_{j}^{n_{k}} y_{(j-1) k}, x_{k}\right)=0, \quad \text { for each } j=1,2, \ldots, m-1
$$

For the case $j=m$, by (4.1), we have

$$
d\left(T_{m}^{n_{k}} y_{(m-1) k}, p\right) \leq\left(1+b_{n_{k}}(p)\right) d\left(y_{(m-1) k}, p\right) \leq\left(1+b_{n_{k}}(p)\right)\left(1+v_{n_{k}}\right)^{m-1} d\left(x_{k}, p\right)
$$

But since $\lim _{k \rightarrow \infty} d\left(x_{k}, p\right)=c$, then

$$
\limsup _{k \rightarrow \infty} d\left(T_{m}^{n_{k}} y_{(m-1) k}, p\right) \leq c
$$

Moreover,

$$
\lim _{k \rightarrow \infty} d\left(\left(1-t_{m k}\right) x_{k} \oplus t_{m k} T_{m}^{n_{k}} y_{(m-1) k}, p\right)=\lim _{k \rightarrow \infty} d\left(x_{k+1}, p\right)=c
$$

Again, by Lemma 4.3, we get that

$$
\lim _{k \rightarrow \infty} d\left(T_{m}^{n_{k}} y_{(m-1) k}, x_{k}\right)=0
$$

Thus, (4.30) and (4.34) imply that

$$
\lim _{k \rightarrow \infty} d\left(T_{j}^{n_{k}} y_{(j-1) k}, x_{k}\right)=0, \quad \text { for each } j=1,2, \ldots, m
$$

(iii) For $j=1$, from (ii), we have

$$
\lim _{k \rightarrow \infty} d\left(T_{1}^{n_{k}} x_{k}, x_{k}\right)=0
$$

If $j=2,3, \ldots, m$, then we have

$$
\begin{aligned}
d\left(T_{j}^{n_{k}} x_{k}, x_{k}\right) & \leq d\left(T_{j}^{n_{k}} x_{k}, T_{j}^{n_{k}} y_{(j-1) k}\right)+d\left(T_{j}^{n_{k}} y_{(j-1) k}, x_{k}\right) \\
& \leq a_{n_{k}}\left(x_{k}\right) d\left(x_{k}, y_{(j-1) k}\right)+d\left(T_{j}^{n_{k}} y_{(j-1) k}, x_{k}\right) \\
& \leq a_{n_{k}}\left(x_{k}\right) t_{(j-1) k} d\left(x_{k}, T_{j-1}^{n_{k}} y_{(j-2) k}\right)+d\left(T_{j}^{n_{k}} y_{(j-1) k}, x_{k}\right) .
\end{aligned}
$$


By (ii) and limsup $\sup _{k \rightarrow \infty} a_{n_{k}}\left(x_{k}\right)=1$, we get

$$
\limsup _{k \rightarrow \infty} d\left(T_{j}^{n_{k}} x_{k}, x_{k}\right)=0, \quad \text { for } j=2,3, \ldots, m .
$$

By (4.36) and (4.38), we have

$$
\lim _{k \rightarrow \infty} d\left(T_{j}^{n_{k}} x_{k}, x_{k}\right)=0, \quad \forall j=1,2, \ldots, m
$$

By the construction of the sequence $\left\{x_{k}\right\}$, we have from (4.35) that

$$
\lim _{k \rightarrow \infty} d\left(x_{k+1}, x_{k}\right)=0
$$

Next, we show that

$$
\lim _{k \rightarrow \infty} d\left(T_{j} x_{k}, x_{k}\right)=0, \quad \forall j=1,2, \ldots, m
$$

It is enough to prove that $d\left(T_{j} x_{k}, x_{k}\right) \rightarrow 0$ as $k \rightarrow \infty$ though 2. Indeed, let $p$ be a quasiperiod of 2 , and let $\varepsilon>0$ be given. Then, there exists $N_{1} \in \mathbb{N}$ such that

$$
\lim _{k \rightarrow \infty} d\left(T_{j} x_{k}, x_{k}\right)<\frac{\varepsilon}{3}, \quad \forall k \in 2 \text { such that } k \geq N_{1} .
$$

By the quasiperiodicity of 2 , for each $l \in \mathbb{N}$, there exists $i_{l} \in \partial$ such that $\left|l-i_{l}\right| \leq p$. Without loss of generality, we can assume that $l \leq i_{l} \leq l+p$ (the proof for the other case is identical). Let $M=\sup \left\{a_{1}(x): x \in C\right\}$. Then, $M \geq 1$. Since $\lim _{l \rightarrow \infty} d\left(x_{l+1}, x_{l}\right)=0$ by (4.40), there exists $N_{2} \in \mathbb{N}$ such that

$$
d\left(x_{l+1}, x_{l}\right)<\frac{\varepsilon}{3 p M}, \quad \forall l \geq N_{2} .
$$

This implies that

$$
d\left(x_{i_{l}}, x_{l}\right) \leq d\left(x_{i_{l}}, x_{i_{l}-1}\right)+\cdots+d\left(x_{l+1}, x_{l}\right) \leq p\left(\frac{\varepsilon}{3 p M}\right)=\frac{\varepsilon}{3 M}
$$

By the definition of $T$, we have

$$
d\left(T_{j} x_{i_{l}}, T_{j} x_{l}\right) \leq M d\left(x_{i_{l}}, x_{l}\right) \leq M\left(\frac{\varepsilon}{3 M}\right)=\frac{\varepsilon}{3}
$$

Let $N=\max \left\{N_{1}, N_{2}\right\}$. Then, for $l \geq N$, we have from (4.42), (4.44), and (4.45) that

$$
d\left(x_{l}, T_{j} x_{l}\right) \leq d\left(x_{l}, x_{i_{l}}\right)+d\left(x_{i_{l}}, T_{j} x_{i_{l}}\right)+d\left(T_{j} x_{i_{l}}, T_{j} x_{l}\right)<\frac{\varepsilon}{3 M}+\frac{\varepsilon}{3}+\frac{\varepsilon}{3} \leq \varepsilon .
$$


To prove that $d\left(T_{j} x_{k}, x_{k}\right) \rightarrow 0$ as $k \rightarrow \infty$ though 2 . Since $\partial=\left\{k \in \mathbb{N}: n_{k+1}=n_{k}+1\right\}$ is quasiperiodic, for each $k \in 2$, we have

$$
\begin{aligned}
d\left(x_{k}, T_{j} x_{k}\right) & \leq d\left(x_{k}, x_{k+1}\right)+d\left(x_{k+1}, T_{j}^{n_{k+1}} x_{k+1}\right)+d\left(T_{j}^{n_{k+1}} x_{k+1}, T_{j}^{n_{k+1}} x_{k}\right)+d\left(T_{j}^{n_{k}+1} x_{k}, T_{j} x_{k}\right) \\
& \leq d\left(x_{k}, x_{k+1}\right)+d\left(x_{k+1}, T_{j}^{n_{k+1}} x_{k+1}\right)+a_{n_{k+1}}\left(x_{k+1}\right) d\left(x_{k+1}, x_{k}\right)+a_{1}\left(x_{k}\right) d\left(T_{j}^{n_{k}} x_{k}, x_{k}\right) .
\end{aligned}
$$

From this, together with (4.39) and (4.40), we can obtain that $d\left(T_{j} x_{k}, x_{k}\right) \rightarrow 0$ as $k \rightarrow \infty$ through 2 .

The following lemmas can be found in [3] (see also [2]).

Lemma 4.9. Let $C$ be a nonempty closed convex subset of $X$, and let $T \in \tau_{r}(C)$. If $\lim _{n \rightarrow \infty} d\left(x_{n}, T x_{n}\right)=0$, then $\lim _{n \rightarrow \infty} d\left(x_{n}, T^{l} x_{n}\right)=0$ for every $l \in \mathbb{N}$.

Lemma 4.10. Let $C$ be a nonempty closed convex subset of $X$, and let $T \in \tau_{r}(C)$. Suppose $\left\{x_{n}\right\}$ is a bounded sequence in $C$ such that $\lim _{n} d\left(x_{n}, T x_{n}\right)=0$ and $\Delta-\lim _{n} x_{n}=w$. Then, Tw $=w$.

By using Lemmas 2.3 and 4.10, we can obtain the following result. We omit the proof because it is similar to the one given in [38].

Lemma 4.11. Let $C$ be a closed convex subset of $X$, and let $T: C \rightarrow C$ be an asymptotic pointwise nonexpansive mapping. Suppose $\left\{x_{n}\right\}$ is a bounded sequence in $C$ such that $\lim _{n} d\left(x_{n}, T\left(x_{n}\right)\right)=0$ and $d\left(x_{n}, v\right)$ converges for each $v \in F(T)$, then $\omega_{w}\left(x_{n}\right) \subset F(T)$. Here, $\omega_{w}\left(x_{n}\right)=\bigcup A\left(\left\{u_{n}\right\}\right)$ where the union is taken over all subsequences $\left\{u_{n}\right\}$ of $\left\{x_{n}\right\}$. Moreover, $\omega_{w}\left(x_{n}\right)$ consists of exactly one point.

Now, we are ready to prove our $\Delta$-convergence theorem.

Theorem 4.12. Let $C$ be a nonempty closed convex subset of $X$ and $T_{1}, \ldots, T_{m} \in \tau_{r}(C)$. Let $\left\{t_{i k}\right\}_{k=1}^{\infty} \subset[\delta, 1-\delta]$ for some $\delta \in(0,1 / 2)$ and $\left\{n_{k}\right\} \subset \mathbb{N}$ be such that $\left\{x_{k}\right\}$ in (4.4) is well defined. Suppose that $F:=\bigcap_{i=1}^{m} F\left(T_{i}\right) \neq \emptyset$ and the set $\partial=\left\{k \in \mathbb{N}: n_{k+1}=1+n_{k}\right\}$ is quasiperiodic. Then, $\left\{x_{k}\right\} \Delta$-converges to a common fixed point of the family $\left\{T_{i}: i=1,2, \ldots, m\right\}$.

Proof. Let $p \in F$, by Lemma $4.8, \lim _{k \rightarrow \infty} d\left(x_{k}, p\right)$ existsm and hence $\left\{x_{k}\right\}$ is bounded. Since $\lim _{k \rightarrow \infty} d\left(x_{k}, T_{j} x_{k}\right)=0$ for all $j=1,2, \ldots, m$, then by Lemma $4.11 \omega_{w}\left(x_{k}\right) \subset F\left(T_{j}\right)$ for all $j=1,2, \ldots, m$, and hence $\omega_{w}\left(x_{k}\right) \subset \bigcap_{j=1}^{m} F\left(T_{j}\right)=F$. Since $\omega_{w}\left(x_{n}\right)$ consists of exactly one point, then $\left\{x_{k}\right\} \Delta$-converges to an element of $F$.

Before proving our strong convergence theorem, we recall that a mapping $T: C \rightarrow C$ is said to be semicompact if $C$ is closed and, for any bounded sequence $\left\{x_{n}\right\}$ in $C$ with $\lim _{n \rightarrow \infty} d\left(x_{n}, T x_{n}\right)=0$, there exists a subsequence $\left\{x_{n_{j}}\right\}$ of $\left\{x_{n}\right\}$ and $x \in C$ such that $\lim _{k \rightarrow \infty} x_{n_{k}}=x$.

Theorem 4.13. Let $C$ be a nonempty closed convex subset of $X$ and $T_{1}, \ldots, T_{m} \in \tau_{r}(C)$ such that $T_{i}^{l}$ is semicompact for some $i \in\{1, \ldots, m\}$ and $l \in \mathbb{N}$. Let $\left\{t_{i k}\right\}_{k=1}^{\infty} \subset[\delta, 1-\delta]$ for some $\delta \in(0,1 / 2)$ and $\left\{n_{k}\right\} \subset \mathbb{N}$ be such that $\left\{x_{k}\right\}$ in (4.4) is well defined. Suppose that $F:=\bigcap_{i=1}^{m} F\left(T_{i}\right) \neq \emptyset$ and the set $\partial=\left\{k \in \mathbb{N}: n_{k+1}=1+n_{k}\right\}$ is quasiperiodic. Then, $\left\{x_{k}\right\}$ converges to a common fixed point of the family $\left\{T_{i}: i=1,2, \ldots, m\right\}$. 
Proof. By Lemma 4.8, we have

$$
\lim _{k \rightarrow \infty} d\left(x_{k}, T_{i} x_{k}\right)=0, \quad \text { for } i=1, \ldots, m
$$

Let $i \in\{1, \ldots, m\}$ be such that $T_{i}^{l}$ is semicompact. Thus, by Lemma 4.9,

$$
\lim _{k \rightarrow \infty} d\left(x_{k}, T_{i}^{l} x_{k}\right)=0
$$

We can also find a subsequence $\left\{x_{n_{j}}\right\}$ of $\left\{x_{k}\right\}$ such that $\lim _{j \rightarrow \infty} x_{k_{j}}=q \in C$. Hence, from (4.48), we have

$$
d\left(q, T_{i} q\right)=\lim _{j \rightarrow \infty} d\left(x_{k_{j}}, T_{i} x_{k_{j}}\right)=0, \quad \forall i=1, \ldots, m
$$

Thus, $q \in F$, and, by Corollary 4.6, $\left\{x_{k}\right\}$ converges to $q$. This completes the proof.

\section{Concluding Remarks}

One may observe that our method can be used to obtain the analogous results for uniformly convex Banach spaces. Let $C$ be a nonempty closed convex subset of a Banach space $X$ and fix $x_{1} \in C$. Define a sequence $\left\{x_{k}\right\}$ in $C$ as

$$
\begin{gathered}
x_{k+1}=\left(1-t_{m k}\right) x_{k}+t_{m k} T_{m}^{n_{k}} y_{(m-1) k} \\
y_{(m-1) k}=\left(1-t_{(m-1) k}\right) x_{k}+t_{(m-1) k} T_{m-1}^{n_{k}} y_{(m-2) k} \\
y_{(m-2) k}=\left(1-t_{(m-2) k}\right) x_{k}+t_{(m-2) k} T_{m-2}^{n_{k}} y_{(m-3) k} \\
\vdots \\
y_{2 k}=\left(1-t_{2 k}\right) x_{k}+t_{2 k} T_{2}^{n_{k}} y_{1 k}, \\
y_{1 k}=\left(1-t_{1 k}\right) x_{k}+t_{1 k} T_{1}^{n_{k}} y_{0 k} \\
y_{0 k}=x_{k}, \quad k \in \mathbb{N},
\end{gathered}
$$

where $T_{1}, \ldots, T_{m} \in \tau_{r}(C), \quad\left\{t_{i k}\right\}_{k=1}^{\infty}$ are sequences in $[0,1]$ for all $i=1,2, \ldots, m$, and $\left\{n_{k}\right\}$ is an increasing sequence of natural numbers.

Theorem 5.1. Let $X$ be a uniformly convex Banach space with the Opial property, and let $C$ be a nonempty closed convex subset of X. Let $T_{1}, \ldots, T_{m} \in \tau_{r}(C),\left\{t_{i k}\right\}_{k=1}^{\infty} \subset[\delta, 1-\delta]$ for some $\delta \in$ $(0,1 / 2)$, and let $\left\{n_{k}\right\} \subset \mathbb{N}$ be such that $\left\{x_{k}\right\}$ in (5.1) is well defined. Suppose that $F:=\bigcap_{i=1}^{m} F\left(T_{i}\right) \neq \emptyset$ and the set $\partial=\left\{k \in \mathbb{N}: n_{k+1}=1+n_{k}\right\}$ is quasiperiodic. Then, $\left\{x_{k}\right\}$ converges weakly to a common fixed point of the family $\left\{T_{i}: i=1,2, \ldots, m\right\}$.

Theorem 5.2. Let $C$ be a nonempty closed convex subset of a uniformly convex Banach space $X$ and $T_{1}, \ldots, T_{m} \in \tau_{r}(C)$ such that $T_{i}^{l}$ is semicompact for some $i \in\{1, \ldots, m\}$ and $l \in \mathbb{N}$. Let $\left\{t_{i k}\right\}_{k=1}^{\infty} \subset$ $[\delta, 1-\delta]$ for some $\delta \in(0,1 / 2)$, and let $\left\{n_{k}\right\} \subset \mathbb{N}$ be such that $\left\{x_{k}\right\}$ in (5.1) is well defined. Suppose that $F:=\bigcap_{i=1}^{m} F\left(T_{i}\right) \neq \emptyset$ and the set $\partial=\left\{k \in \mathbb{N}: n_{k+1}=1+n_{k}\right\}$ is quasiperiodic. Then, $\left\{x_{k}\right\}$ converges strongly to a common fixed point of the family $\left\{T_{i}: i=1,2, \ldots, m\right\}$. 


\section{Acknowledgments}

This research is (partially) supported by the Centre of Excellence in Mathematics, the Commission on Higher Education, Thailand. The first author also thanks the Graduate School of Chiang Mai University, Thailand.

\section{References}

[1] W. A. Kirk and H.-K. Xu, "Asymptotic pointwise contractions," Nonlinear Analysis, vol. 69, no. 12, pp. 4706-4712, 2008.

[2] N. Hussain and M. A. Khamsi, "On asymptotic pointwise contractions in metric spaces," Nonlinear Analysis, vol. 71, no. 10, pp. 4423-4429, 2009.

[3] W. M. Kozlowski, "Fixed point iteration processes for asymptotic pointwise nonexpansive mappings in Banach spaces," Journal of Mathematical Analysis and Applications, vol. 377, no. 1, pp. 43-52, 2011.

[4] A. R. Khan, A.-A. Domlo, and H. Fukhar-ud-din, "Common fixed points Noor iteration for a finite family of asymptotically quasi-nonexpansive mappings in Banach spaces," Journal of Mathematical Analysis and Applications, vol. 341, no. 1, pp. 1-11, 2008.

[5] M. R. Bridson and A. Haefliger, Metric Spaces of Non-Positive Curvature, vol. 319 of Grundlehren der Mathematischen Wissenschaften, Springer, Berlin, Germany, 1999.

[6] W. A. Kirk, "Fixed point theorems in CAT(0) spaces and $\mathbb{R}$-trees," Fixed Point Theory and Applications, no. 4, pp. 309-316, 2004.

[7] K. S. Brown, Buildings, Springer, New York, NY, USA, 1989.

[8] K. Goebel and S. Reich, Uniform Convexity, Hyperbolic Geometry, and Nonexpansive Mappings, vol. 83 of Monographs and Textbooks in Pure and Applied Mathematics, Marcel Dekker, New York, NY, USA, 1984.

[9] W. A. Kirk, "Geodesic geometry and fixed point theory," in Seminar of Mathematical Analysis, vol. 64 of Colecc. Abierta, pp. 195-225, Universidad de Sevilla Secr. Publ., Seville, Spain, 2003.

[10] W. A. Kirk, "Geodesic geometry and fixed point theory. II," in International Conference on Fixed Point Theory and Applications, pp. 113-142, Yokohama Publishers, Yokohama, Japan, 2004.

[11] S. Dhompongsa, A. Kaewkhao, and B. Panyanak, "Lim's theorems for multivalued mappings in CAT(0) spaces," Journal of Mathematical Analysis and Applications, vol. 312, no. 2, pp. 478-487, 2005.

[12] P. Chaoha and A. Phon-on, "A note on fixed point sets in CAT(0) spaces," Journal of Mathematical Analysis and Applications, vol. 320, no. 2, pp. 983-987, 2006.

[13] L. Leustean, "A quadratic rate of asymptotic regularity for CAT(0)-spaces," Journal of Mathematical Analysis and Applications, vol. 325, no. 1, pp. 386-399, 2007.

[14] S. Dhompongsa and B. Panyanak, "On $\Delta$-convergence theorems in CAT(0) spaces," Computers $\mathcal{E}$ Mathematics with Applications, vol. 56, no. 10, pp. 2572-2579, 2008.

[15] N. Shahzad and J. Markin, "Invariant approximations for commuting mappings in CAT(0) and hyperconvex spaces," Journal of Mathematical Analysis and Applications, vol. 337, no. 2, pp. 1457-1464, 2008.

[16] N. Shahzad, "Fixed point results for multimaps in CAT(0) spaces," Topology and Its Applications, vol. 156, no. 5, pp. 997-1001, 2009.

[17] R. Espínola and A. Fernández-León, "CAT(k)-spaces, weak convergence and fixed points," Journal of Mathematical Analysis and Applications, vol. 353, no. 1, pp. 410-427, 2009.

[18] A. Razani and H. Salahifard, "Invariant approximation for CAT(0) spaces," Nonlinear Analysis, vol. 72, no. 5, pp. 2421-2425, 2010.

[19] S. Saejung, "Halpern's iteration in CAT(0) spaces," Fixed Point Theory and Applications, vol. 2010, Article ID 471781, 13 pages, 2010.

[20] A. R. Khan, M. A. Khamsi, and H. Fukhar-ud-din, "Strong convergence of a general iteration scheme in CAT(0) spaces," Nonlinear Analysis, vol. 74, no. 3, pp. 783-791, 2011.

[21] S. H. Khan and M. Abbas, "Strong and $\Delta$-convergence of some iterative schemes in CAT(0) spaces," Computers \& Mathematics with Applications, vol. 61, no. 1, pp. 109-116, 2011.

[22] A. Abkar and M. Eslamian, "Common fixed point results in CAT(0) spaces," Nonlinear Analysis, vol. 74, no. 5, pp. 1835-1840, 2011.

[23] M. Bestvina, "R-trees in topology, geometry, and group theory," in Handbook of Geometric Topology, pp. 55-91, North-Holland, Amsterdam, The Netherlands, 2002. 
[24] C. Semple and M. Steel, Phylogenetics, vol. 24 of Oxford Lecture Series in Mathematics and Its Applications, Oxford University Press, Oxford, UK, 2003.

[25] R. Espínola and W. A. Kirk, "Fixed point theorems in $\mathbb{R}$-trees with applications to graph theory," Topology and Its Applications, vol. 153, no. 7, pp. 1046-1055, 2006.

[26] W. A. Kirk, "Some recent results in metric fixed point theory," Journal of Fixed Point Theory and Applications, vol. 2, no. 2, pp. 195-207, 2007.

[27] S. Dhompongsa, W. A. Kirk, and B. Sims, "Fixed points of uniformly Lipschitzian mappings," Nonlinear Analysis, vol. 65, no. 4, pp. 762-772, 2006.

[28] W. A. Kirk and B. Panyanak, "A concept of convergence in geodesic spaces," Nonlinear Analysis, vol. 68, no. 12, pp. 3689-3696, 2008.

[29] T. C. Lim, "Remarks on some fixed point theorems," Proceedings of the American Mathematical Society, vol. 60, pp. 179-182, 1976.

[30] S. Dhompongsa, W. A. Kirk, and B. Panyanak, "Nonexpansive set-valued mappings in metric and Banach spaces," Journal of Nonlinear and Convex Analysis, vol. 8, no. 1, pp. 35-45, 2007.

[31] W. A. Kirk, "A fixed point theorem for mappings which do not increase distances," The American Mathematical Monthly, vol. 72, pp. 1004-1006, 1965.

[32] K. Goebel and W. A. Kirk, "A fixed point theorem for asymptotically nonexpansive mappings," Proceedings of the American Mathematical Society, vol. 35, pp. 171-174, 1972.

[33] R. Espínola and N. Hussain, "Common fixed points for multimaps in metric spaces," Fixed Point Theory and Applications, vol. 2010, Article ID 204981, 14 pages, 2010.

[34] P. Pasom and B. Panyanak, "Common fixed points for asymptotic pointwise nonexpansive mappings," Fixed Point Theory. to appear.

[35] R. E. Bruck, Jr., "A common fixed point theorem for a commuting family of nonexpansive mappings," Pacific Journal of Mathematics, vol. 53, pp. 59-71, 1974.

[36] Z.-H. Sun, "Strong convergence of an implicit iteration process for a finite family of asymptotically quasi-nonexpansive mappings," Journal of Mathematical Analysis and Applications, vol. 286, no. 1, pp. 351-358, 2003.

[37] M. A. Khamsi and A. R. Khan, "Inequalities in metric spaces with applications," Nonlinear Analysis, vol. 74, no. 12, pp. 4036-4045, 2011.

[38] B. Nanjaras and B. Panyanak, "Demiclosed principle for asymptotically nonexpansive mappings in CAT(0) spaces," Fixed Point Theory and Applications, vol. 2010, Article ID 268780, 14 pages, 2010.

[39] R. Bruck, T. Kuczumow, and S. Reich, "Convergence of iterates of asymptotically nonexpansive mappings in Banach spaces with the uniform Opial property," Colloquium Mathematicum, vol. 65, no. 2, pp. 169-179, 1993. 


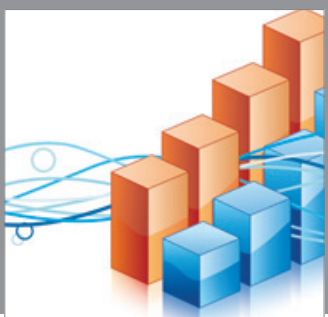

Advances in

Operations Research

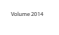

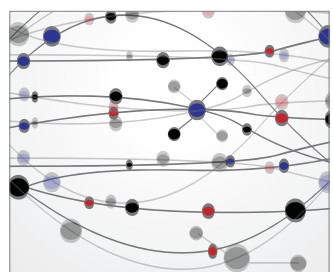

\section{The Scientific} World Journal
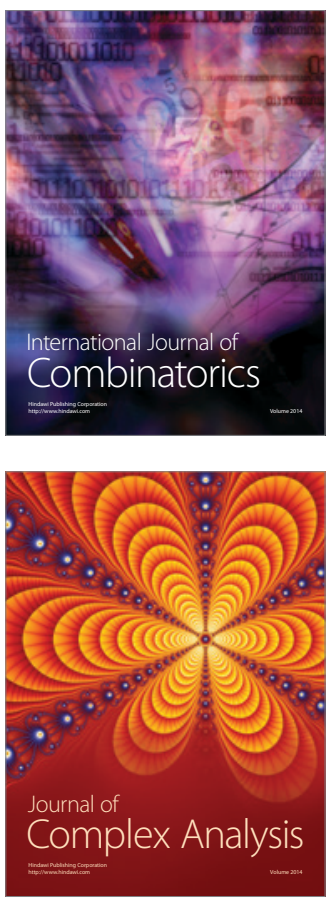

International Journal of

Mathematics and

Mathematical

Sciences
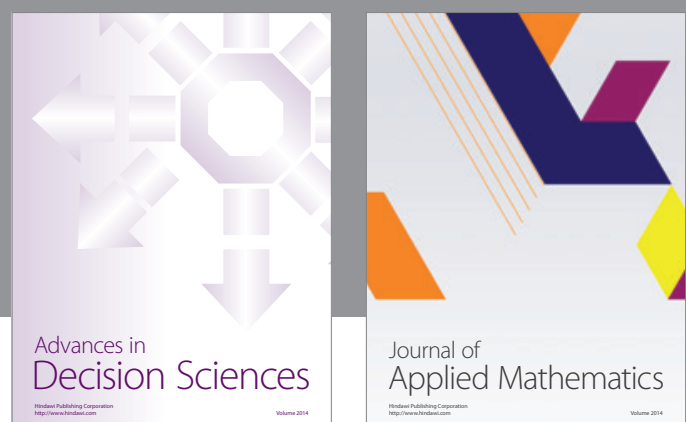

Journal of

Applied Mathematics
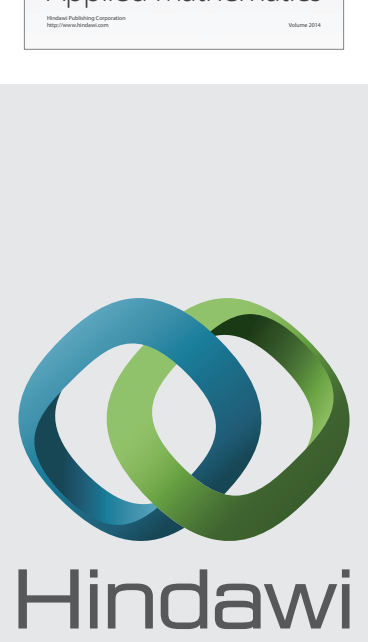

Submit your manuscripts at http://www.hindawi.com
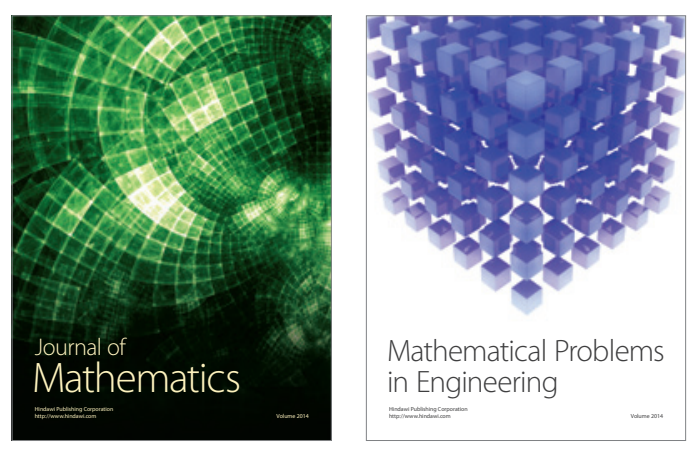

Mathematical Problems in Engineering
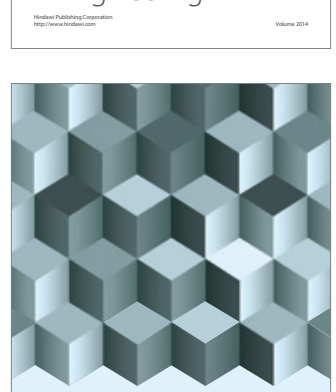

Journal of

Function Spaces
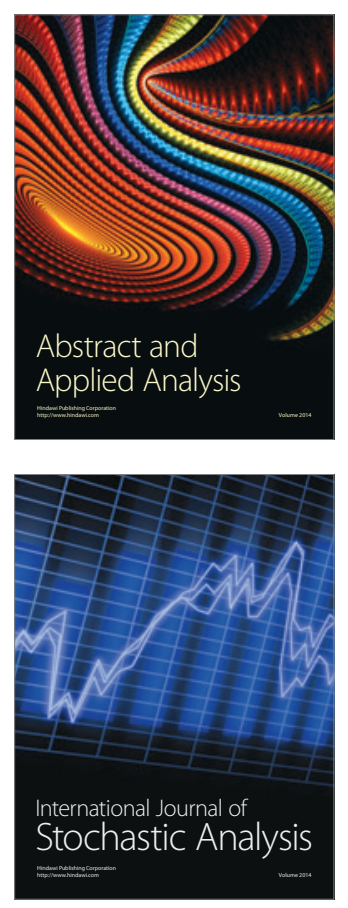

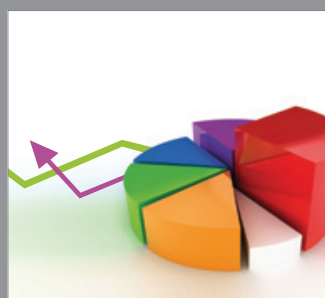

ournal of

Probability and Statistics

Promensencen
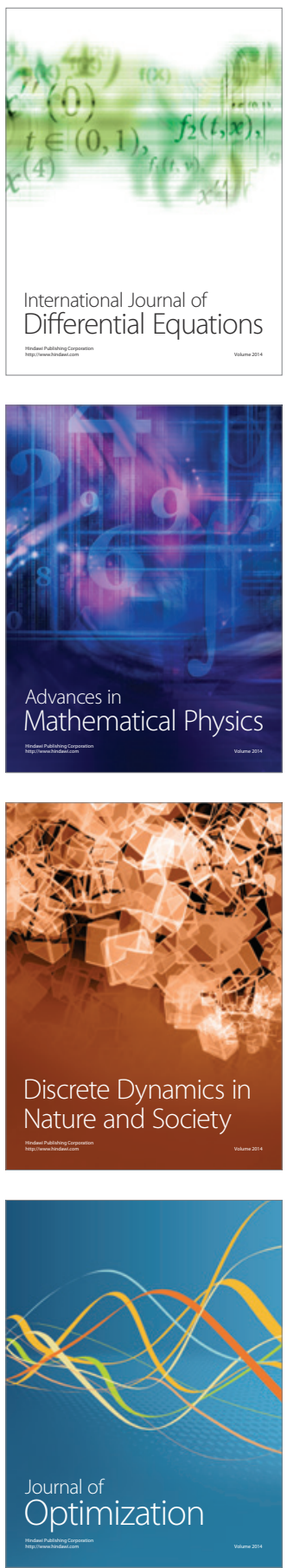